\title{
Van Niel International Prize for Studies in Bacterial Systematics, awarded by the University of Queensland Awarded in 2008 to Matthew David Collins
}

\author{
International Committee on Systematics of Prokaryotes
}

Correspondence

B. J. Tindall

bti@dsmz.de
The Senate of the University of Queensland on the recommendation of the International Committee for Systematics of Prokaryotes is pleased to present the Van Niel International Prize for Studies in Bacterial Systematics for the triennium 2006-2008 to Professor Matthew David Collins in recognition of the contributions made to the field of bacterial systematics. The award, established by Professor V. B. D. Skerman of the University of Queensland, honours the contribution of scholarship in the field of microbiology of Professor Cornelis Bernardus van Niel.
Professor Matthew David Collins (known to all as Dave Collins) studied at the University of Newcastle (UK) for both his BSc (1975) and $\mathrm{PhD}$ (1978) degrees. It was at the University of Newcastle that he was introduced to the investigation of microbial chemotaxonomy in the laboratories of Professor Dave E. Minnikin and Professor Mike Goodfellow and undertook his $\mathrm{PhD}$ research on the lipids in coryneform taxonomy. During his post-doctoral studies, Professor Collins moved to the laboratory of Dr Dorothy Jones at the University of Leicester (1978-1980), where he continued to work on the chemotaxonomy and taxonomy of Gram-positive bacteria. In 1980, he took up a permanent position at the National Institute for Research in Dairying (NIRD), Shinfield, Reading, UK. Here he held the position of Curator of the National Collection of Dairy Organisms (NCDO), later becoming the National Collection of Food Bacteria (NCFB). The NIRD underwent structural change in 1992 to become the Institute of Food Research, AFRC, Reading Laboratory. With the closure of the AFRC Reading Laboratory in 1999, Professor Collins moved to the University of Reading, taking up a position as Professor of Molecular Systematics.

Initially concentrating on Gram-positive bacteria, he studied quinone, polar lipid and fatty acid compositions of microbes at a time when technologies such as capillary chromatography and HPLC separation were just becoming generally available. His contribution to the study of quinone composition was not just restricted to routine screening, but also included the development of HPLCbased methods for their separation, as well as detailed structural elucidation of a number of novel compounds. His studies form the basis of the modern taxonomy of
Gram-positive taxa and the methods he developed, as well as the chemotaxonomic data that were collected in cooperation or association with other research groups, are still in use by researchers in the field. Towards the end of the 1980s, Professor Collins was introduced to methods for $16 \mathrm{~S}$ rRNA gene sequencing, which at that time were in transition from the reverse transcriptase methods to PCRbased techniques. He quickly set up one of the leading laboratories in the UK for the sequencing of the 16S rRNA gene and produced a steady flow of quality papers, which still form the basis for the taxonomy of many groups of micro-organisms. This high productivity led to numerous international collaborations and a substantial number of publications (over 500). Many of his publications are regularly cited and he represents one of the most highly cited living bacterial taxonomists. His research on the molecular and chemical taxonomy of Gram-positive bacteria clarified many taxonomic uncertainties and provided a lasting stable platform on which the taxonomy of the Gram-positive bacteria continues to develop.

The above citation accompanies the prize, which will also be announced at the IUMS Bacteriology and Applied Microbiology Congress in Istanbul, Turkey, 5-9 August 2008. The International Committee on Systematics of Prokaryotes wishes to congratulate Professor Matthew David Collins on being awarded the prize in recognition of his contribution to prokaryote systematics.

Citation prepared by the University of Queensland and submitted on their behalf and that of the International Committee on Systematics of Prokaryotes by B. J. Tindall. 